SRNL-STI-2013-00506 Rev. 0

Keywords: polymer, tritium, radiolytic gas production rate

Retention: Permanent

\title{
Radiolytic Gas Production Rates of Polymers Exposed to Tritium Gas
}

Elliot A. Clark

Materials Science \& Technology

31 August 2013

Savannah River National Laboratory Savannah River Nuclear Solutions, LLC Aiken, SC 29808

Prepared for the U.S. Department of Energy under

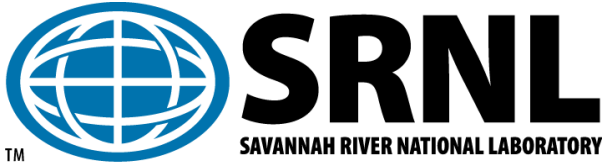
contract number DE-AC09-08SR22470. 


\section{DISCLAIMER}

This work was prepared under an agreement with and funded by the U.S. Government. Neither the U.S. Government or its employees, nor any of its contractors, subcontractors or their employees, makes any express or implied:

1. warranty or assumes any legal liability for the accuracy, completeness, or for the use or results of such use of any information, product, or process disclosed; or

2. representation that such use or results of such use would not infringe privately owned rights; or

3. endorsement or recommendation of any specifically identified commercial product, process, or service.

Any views and opinions of authors expressed in this work do not necessarily state or reflect those of the United States Government, or its contractors, or subcontractors.

\section{Printed in the United States of America \\ Prepared for \\ U.S. Department of Energy}




\section{EXECUTIVE SUMMARY}

Data from previous reports on studies of polymers exposed to tritium gas is further analyzed to estimate rates of radiolytic gas production. Also, graphs of gas release during tritium exposure from ultrahigh molecular weight polyethylene (UHMW-PE), polytetrafluoroethylene (PTFE, a trade name is Teflon ${ }^{\circledR}$ ), and Vespel ${ }^{\circledR}$ polyimide are re-plotted as moles of gas as a function of time, which is consistent with a later study of tritium effects on various formulations of the elastomer ethylene-propylene-diene monomer (EPDM).

These gas production rate estimates may be useful while considering using these polymers in tritium processing systems. These rates are valid at least for the longest exposure times for each material, two years for UHMW-PE, PTFE, and Vespel ${ }^{\circledR}$, and fourteen months for filled and unfilled EPDM. Note that the production "rate" for Vespel ${ }^{\circledR}$ is a quantity of $\mathrm{H}_{2}$ produced during a single exposure to tritium, independent of length of time.

The larger production rate per unit mass for unfilled EPDM results from the lack of filler- the carbon black in filled EPDM does not produce $\mathrm{H}_{2}$ or HT. This is one aspect of how inert fillers reduce the effects of ionizing radiation on polymers.

\begin{tabular}{|c|c|}
\hline Material & $\begin{array}{l}\text { Radiolytic Production Rate, initially exposed to } 1 \mathrm{~atm} \\
\text { tritium at ambient temperature in closed container }\end{array}$ \\
\hline UHMW-PE (unfilled) & $1.2 * 10^{-3} \mathrm{~mol} \mathrm{H}_{2} / \mathrm{g}$ UHMW-PE/year \\
\hline PTFE (unfilled) & $4.0 * 10^{-5} \mathrm{~mol}(\mathrm{H}, \mathrm{T}) \mathrm{F} / \mathrm{g}$ PTFE$/$ year \\
\hline Vespel® SP-1 & $1.1 * 10^{-4} \mathrm{~mol} \mathrm{H}_{2} / \mathrm{g}$ Vespel $\AA /$ single exposure \\
\hline EPDM (filled) & $1.04 * 10^{-3} \mathrm{~mol}$ gas $\left(\mathrm{H}_{2}, \mathrm{HT}\right) / \mathrm{g}$ filled EPDM/year \\
\hline EPDM (unfilled) & $2.84 * 10^{-3} \mathrm{~mol}$ gas $\left(\mathrm{H}_{2}, \mathrm{HT}\right) / \mathrm{g}$ UNfilled EPDM/year \\
\hline
\end{tabular}




\section{CONTENTS}

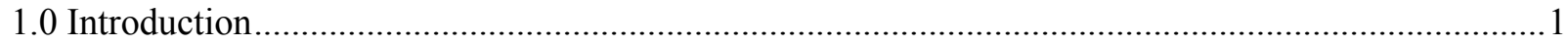

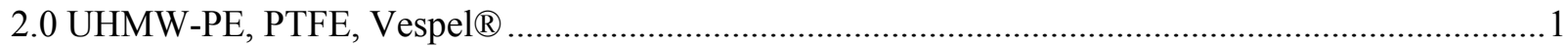

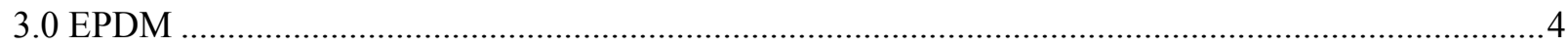

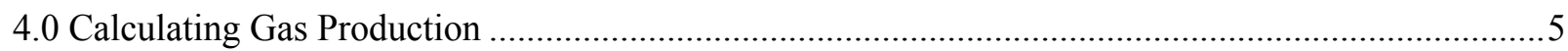

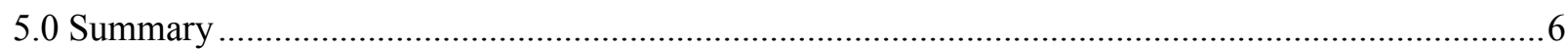

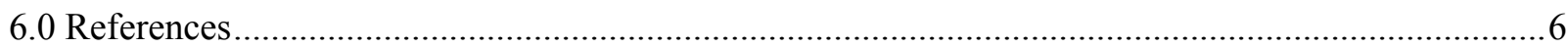

\section{FIGURES}

Figure 2-1 Moles of Gas in Container (Total. $\mathrm{H}_{2}, \mathrm{~T}_{2}$ ) and a liner least squares fit to the Total gas for a series of exposures of UHMW-PE samples to tritium gas initially at $1 \mathrm{~atm}$.....................2

Figure 2-2 Moles of Gas in Container (Total. $\mathrm{H}_{2}, \mathrm{~T}_{2}$ ) and a liner least squares fit to the Total gas for a series of exposures of PTFE (unfilled) samples to tritium gas initially at $1 \mathrm{~atm} . . . \ldots \ldots \ldots . . . . . .2$

Figure 2-3 Moles of Gas in Container (Total. $\mathrm{H}_{2}, \mathrm{~T}_{2}$ ) for a series of exposures of Vespel® SP-1 samples to tritium gas initially at $1 \mathrm{~atm}$. The fit is the average value of the moles $\mathrm{H}_{2}$ produced.

Figure 3-1 Moles of Gas in Container (Total. $\mathrm{H}_{2}, \mathrm{HT}, \mathrm{T}_{2},{ }^{3} \mathrm{He}$, residuals) for a series of exposures of carbon black-filled Nordel ${ }^{\circledR}$ samples to tritium gas initially at 1 atm. Initial production mainly HT, then $\mathrm{H}_{2}$ becomes dominant. Filled Royalene ${ }^{\circledR}$ and unfilled versions of both resins behave the same. (Previously reported [2]) .................................... 4

Figure 3-2 Moles of Gas Produced per unit polymer mass for a series of exposures of samples of four EPDM formulations to tritium gas initially at 1 atm in closed containers. Exposure data and linear fits to Filled and Unfilled materials are indicated.

\section{TABLE}

Table 5-1 Summary of Radiolytic Production Rates for Polymers Studied 


\subsection{Introduction}

For more than a decade, the effects of tritium gas on various thermoplastics [1] and elastomers [2] have been studied at the Savannah River Site. In spite of the well-known degradation of polymers by ionizing radiation, polymers have unique properties that make their use in tritium facilities inevitable. The unique properties of polymers are mainly related to sealing applications- components such as O-ring seals, valve stem tips, and valve packing. In some cases, alternative materials exist, such as Helicoflex ${ }^{\circledR}$ all-metal gaskets. Often, automatic valves having metal stem tips require excessively large actuators, so polymer stem tips are used to allow smaller actuators to be used in restricted confinement glovebox space. (Metal stem tips can eventually result in deformation and degradation of the valve seat, so even all-metal valves have a finite life.) The inevitable degradation and routine replacement of components is accepted as a cost of facility operation.

The goal of these studies was to characterize the rate of degradation of material samples exposed to tritium gas with time. In addition to characterizing the effects of tritium gas on the material samples using visual inspection, Dynamic Mechanical Analysis, bend testing, and other methods, the radiolytic production of gases during tritium exposure was also monitored by analyzing the gas in the closed sample exposure container after each exposure test was completed. The total pressure at the end of exposure was measured using calibrated volumes and pressure measurements when the exposure gas was unloaded. Also, "grab" samples of unloaded exposure gas were analyzed by mass spectroscopy to determine the species in the gas after exposure.

The purpose of this report is to present further analysis of gas evolution data from the earlier reports in the form of gas production rates. These rates can be used to estimate the production of various species if the specific polymers are used in tritium service. Also, the gas evolution versus time data from the earlier report on thermoplastics [1] is presented in a clearer form (moles gas versus time) consistent with that used in the later elastomer report [2].

\subsection{UHMW-PE, PTFE, Vespel ${ }^{\circledR}$}

In the earlier report [1], the gas production data was presented as separate graphs of total pressure versus time and concentration versus time. Using the estimated free volume of the containers used for this study $(19 \mathrm{cc})$, and assuming temperature of $298 \mathrm{~K}$, the data is graphed as moles of gas versus exposure time (Figs. 2-1, 2-2, 2-3). As discussed previously [1], the copious production of protium upon irradiation is a well-known property of polyethylene (Fig. 2-1). The reduction in pressure during unfilled PTFE exposure (Fig. 2-2) is interpreted as resulting from formation of HF and TF- this species is a "sticky" gas at ambient temperature, and so condenses on the surfaces of the samples and the container, reducing the pressure. Also plotted in Figs 2-1 and 2-2 is a linear least-squares fit to the moles total gas versus exposure time. Using the average mass of UHMW-PE $(2.06 \mathrm{~g})$ and PTFE $(4.17 \mathrm{~g})$ in the respective exposure experiments and the slopes of the linear fits, the production rate of $\mathrm{H}_{2}$ from UHMW-PE in tritium is found to be $1.2 * 10^{-3} \mathrm{~mol} \mathrm{H}_{2} / \mathrm{g}$ UHMW-PE/year, and the production rate of $(\mathrm{H}, \mathrm{T}) \mathrm{F}$ is found to be $4.0^{*} 10^{-5} \mathrm{~mol}(\mathrm{H}, \mathrm{T}) \mathrm{F} / \mathrm{g}$ PTFE/year. The larger average sample mass of PTFE reflects the greater density of PTFE $(2.20 \mathrm{~g} / \mathrm{cc})$ than UHMW-PE $(0.93 \mathrm{~g} / \mathrm{cc})$ [1]. 


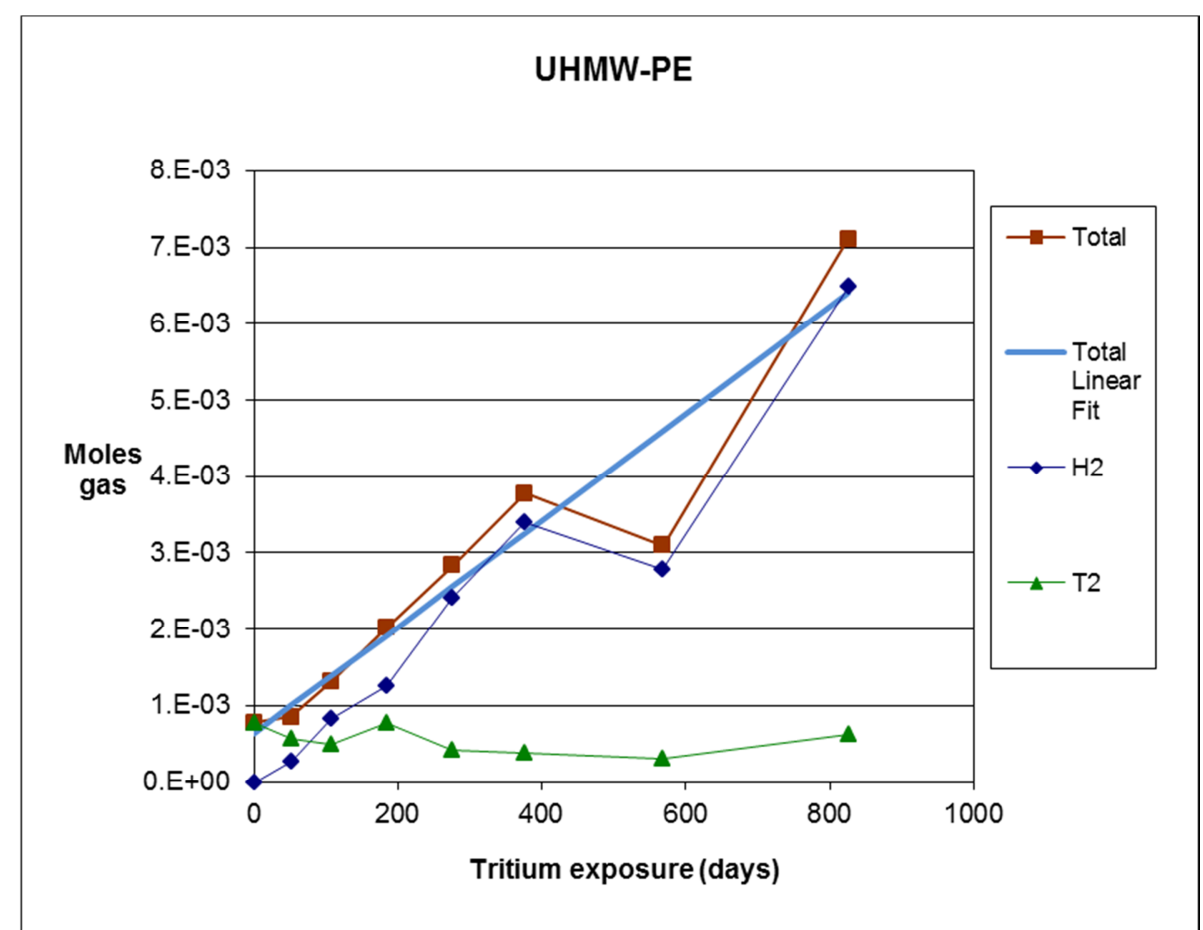

Figure 2-1 Moles of Gas in Container (Total. $\mathrm{H}_{2}, \mathrm{~T}_{2}$ ) and a liner least squares fit to the Total gas for a series of exposures of UHMW-PE samples to tritium gas initially at 1 atm.

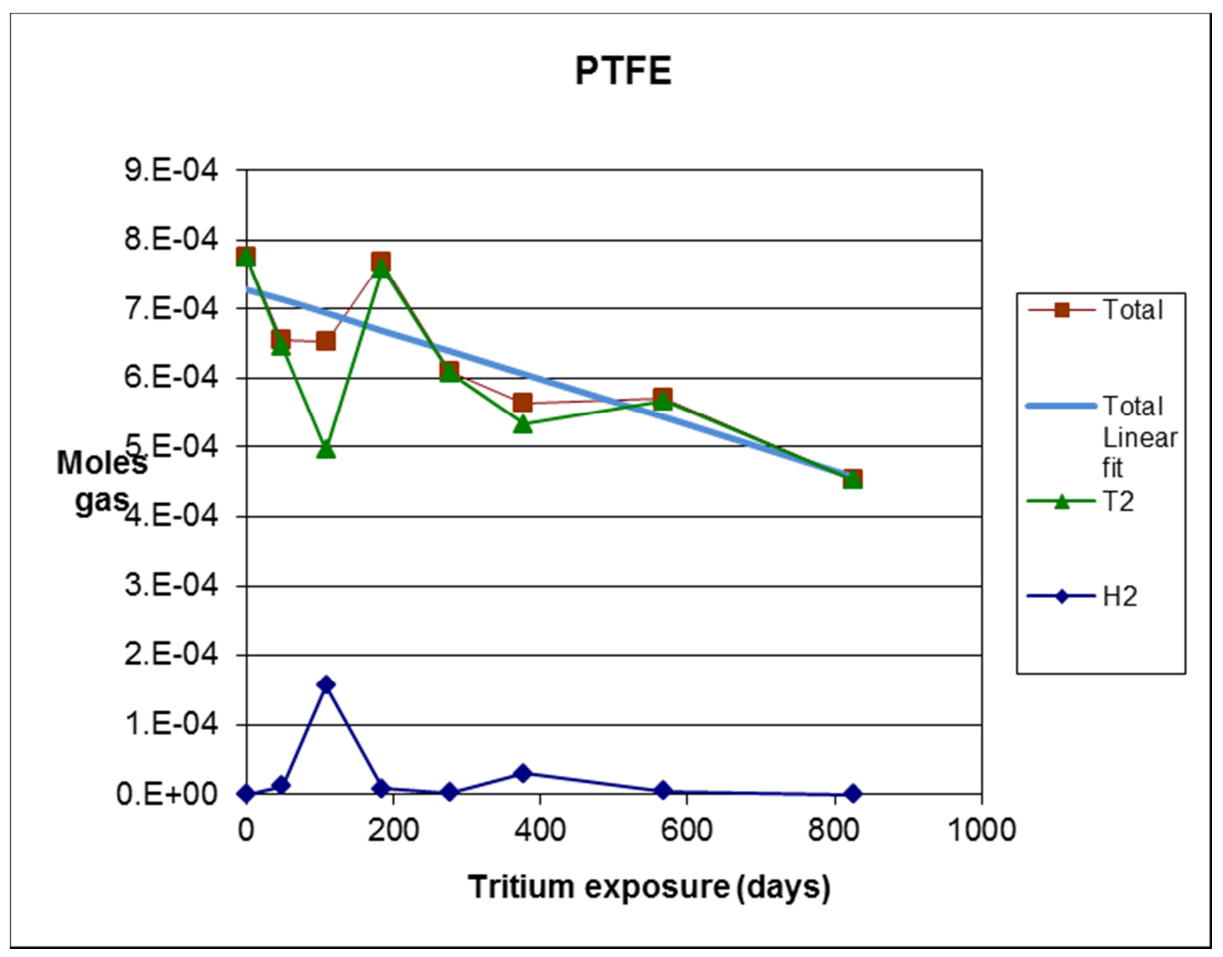

Figure 2-2 Moles of Gas in Container (Total. $\left.\mathrm{H}_{2}, \mathrm{~T}_{2}\right)$ and a liner least squares fit to the Total gas for a series of exposures of PTFE (unfilled) samples to tritium gas initially at $1 \mathrm{~atm}$. 
No fit of gas production as a function of time was made for Vespel®, as there was no trend to the total pressure versus time data (Fig. 2-3). Note that a mixture of about $41 \%$ protium and $59 \%$ tritium appears after at most only three months exposure of Vespel ${ }^{\circledR}$ (Fig. 2-3), which remains constant at longer exposures. It does appear that when Vespel ${ }^{\circledR}$ is exposed to tritium, protium is exchanged and the exposure gas quickly becomes a mixture of $\mathrm{H}_{2}$ and $\mathrm{T}_{2}$. For one atmosphere tritium gas at the beginning, this is $7.8^{*} 10^{-4} \mathrm{~mol} \mathrm{~T}_{2}$ that becomes a mixture of $3.2 * 10^{-4} \mathrm{~mol} \mathrm{H}_{2}$ and $4.6^{*} 10^{-4} \mathrm{~mol} \mathrm{~T}_{2}\left(41 \% \mathrm{H}_{2}, 59 \% \mathrm{~T}_{2}\right)$ after at most a few months, and remains so for at least two years. The average Vespel® sample mass was $3.01 \mathrm{~g}$, so each exposure of Vespel ${ }^{\circledR}$ to pure tritium gas at one atmosphere resulted in $1.1 * 10^{-4} \mathrm{~mol} \mathrm{H}_{2} / \mathrm{g}$ (Vespel $\left.{ }^{\circledR}\right) /$ single exposure, independent of time for at least two years. More research is required to determine how quickly the stable mixture concentration of $\mathrm{T}_{2}$ and $\mathrm{H}_{2}$ becomes after Vespel ${ }^{\circledR}$ contacts tritium- the ratio was achieved in the shortest exposure used in the study [1].

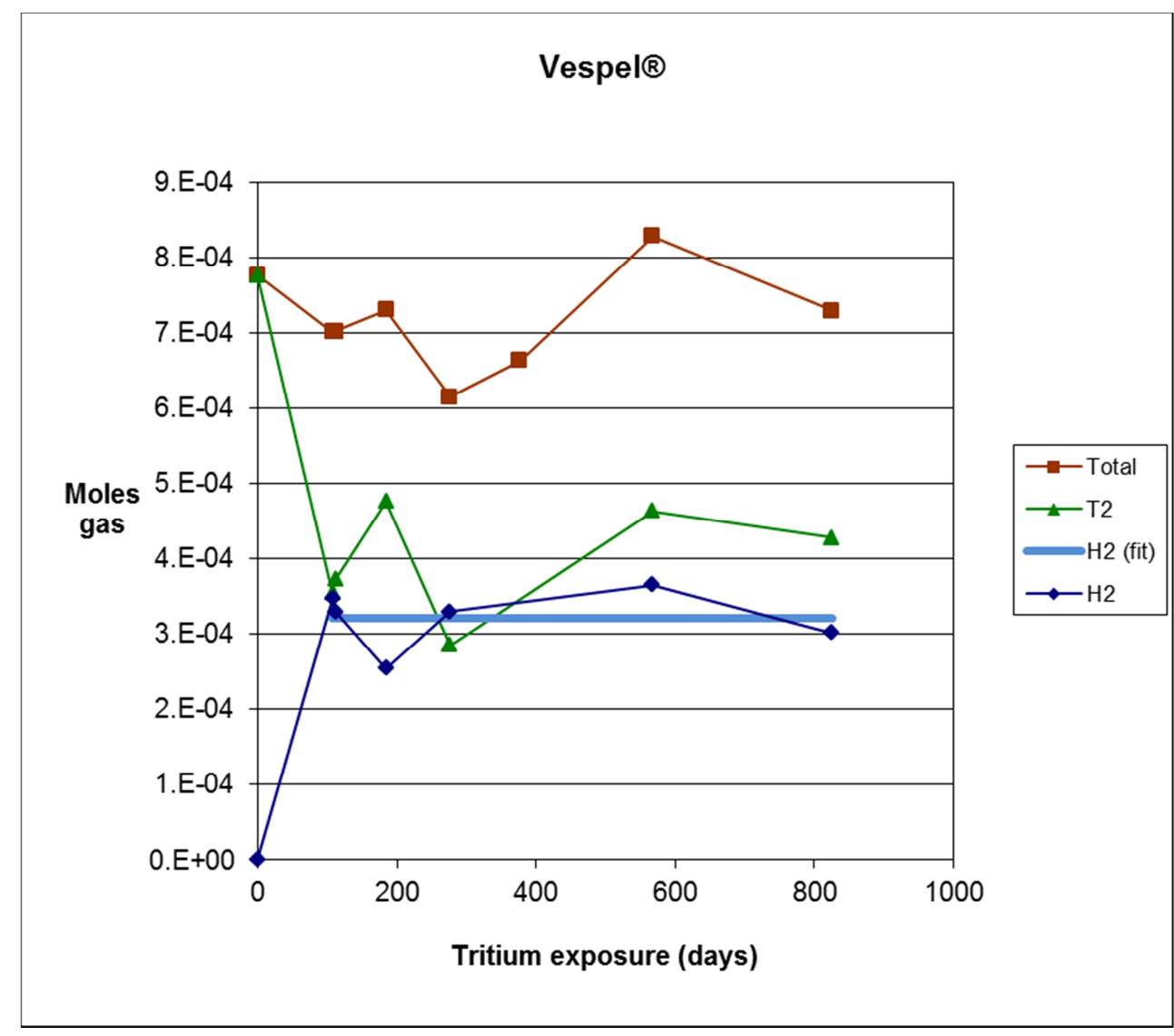

Figure 2-3 Moles of Gas in Container (Total. $\mathrm{H}_{2}, \mathrm{~T}_{2}$ ) for a series of exposures of Vespel ${ }^{\circledR} \mathrm{SP}-1$ samples to tritium gas initially at $1 \mathrm{~atm}$. The fit is the average value of the moles $\mathrm{H}_{2}$ produced. 


\subsection{EPDM}

The gas radiologically produced by EPDM samples exposed to tritium was at first predominantly HT and later predominantly $\mathrm{H}_{2}$ (Fig. 3-1) so that over time a mixture of $\mathrm{HT}$ and $\mathrm{H}_{2}$ is created. (The original purpose of the previous study was to compare the tritium compatibility of two different EPDM resins, Nordel ${ }^{\circledR}$ and Royalene ${ }^{\circledR}[2]$.)

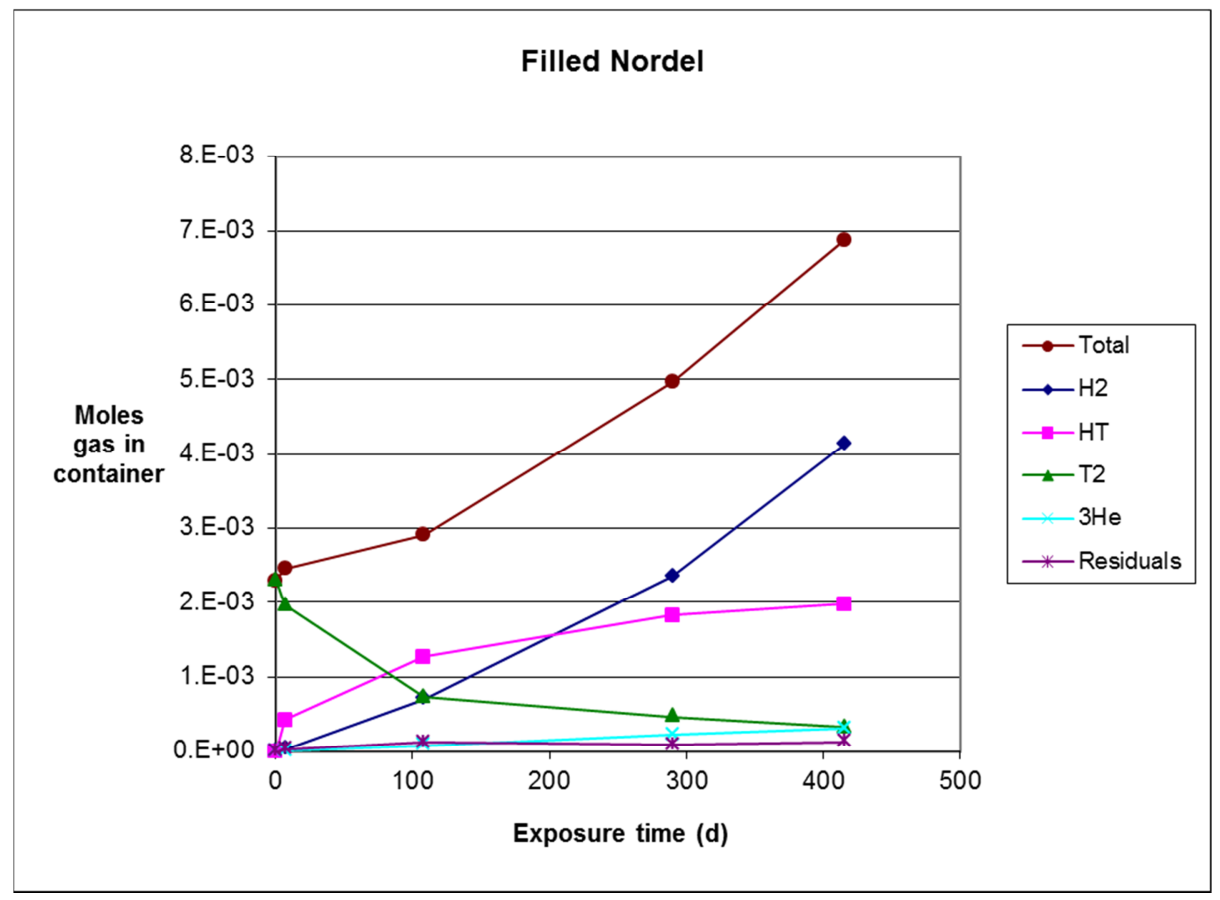

Figure 3-1 Moles of Gas in Container (Total. $\mathrm{H}_{2}, \mathrm{HT}, \mathrm{T}_{2},{ }^{3} \mathrm{He}$, residuals) for a series of exposures of carbon black-filled Nordel ${ }^{\circledR}$ samples to tritium gas initially at $1 \mathbf{a t m}$. Initial production mainly $\mathrm{HT}$, then $\mathrm{H}_{2}$ becomes dominant. Filled Royalene ${ }^{\circledR}$ and unfilled versions of both resins behave the same. (Previously reported [2]).

To obtain a useful gas production rate, the total gas production data (sum of $\mathrm{H}_{2}, \mathrm{HT}, \mathrm{T}_{2},{ }^{3} \mathrm{He}$, residuals produced) from all four materials studied (Filled and Unfilled Nordel ${ }^{\circledR}$, Filled and Unfilled Royalene ${ }^{\circledR}$ ) were divided by the sample mass of each exposure (Fig. 3-2). The gas production per unit polymer mass from the unfilled formulations was significantly greater than the carbon-black-filled, which is expected because the carbon filler material does not undergo radiolysis. The total gas creation rates were $1.04 * 10^{-3}$ $\mathrm{mol}$ gas/g filled EPDM/year and $2.84^{*} 10^{-3} \mathrm{~mol}$ gas/g unfilled EPDM/year. The unfilled EPDM formulations were specially made for this study, and are not commercially available. The vast majority of commercially available EPDM is filled, so the gas creation rate from EPDM used for estimating gas creation rates in tritium facilities should be $1.04 * 10^{-3} \mathrm{~mol}$ gas $/ \mathrm{g}$ filled EPDM/year. It is noteworthy that the gas production rate of EPDM is almost as high as that of UHMW-PE. The production of ${ }^{3} \mathrm{He}$ was that predicted from the total amount of tritium in the exposure containers (discussed previously [2]). (The 
average mass of samples was $4.31 \mathrm{~g}$ for filled $\operatorname{Nordel}{ }^{\circledR}, 1.83 \mathrm{~g}$ for filled Royalene ${ }^{\circledR}, 1.38 \mathrm{~g}$ for unfilled Nordel ${ }^{\circledR}$, and $1.37 \mathrm{~g}$ for unfilled Royalene ${ }^{\circledR}$. The filled Nordel ${ }^{\circledR}$ samples came from a thicker sheet.)

Note that there appears to be an "incubation time" in the production of gas from EPDM (Fig. 3-2)- the moles of gas produced per gram of polymer are lower than the linear fit for all four materials. This could reflect establishing sufficient tritium dissolved throughout the polymer initially. The linear fit was chosen to simplify the estimation method for gas production for this material (Section 4.0).

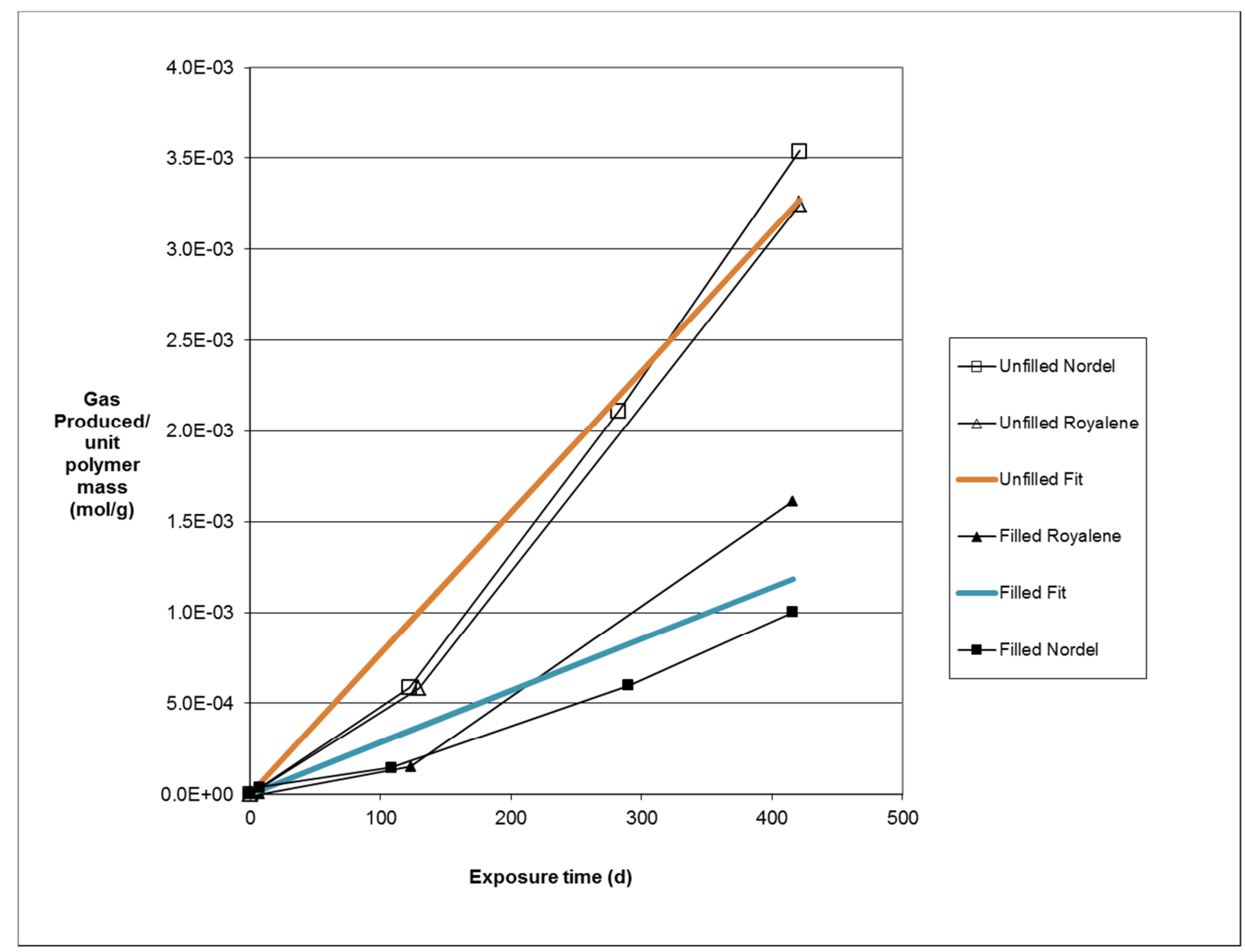

Figure 3-2 Moles of Gas Produced per unit polymer mass for a series of exposures of samples of four EPDM formulations to tritium gas initially at 1 atm in closed containers. Exposure data and linear fits to Filled and Unfilled materials are indicated.

\subsection{Calculating Gas Production}

Molecular gases such as $\mathrm{T}_{2}$ dissolve in polymers proportional to the partial pressure of the gas [3]. The rates of radiolytic gas production reported here are for initially 1 atmosphere tritium. So, if a given polymer is normally exposed on average to a tritium partial pressure of $\mathrm{p}_{\mathrm{T}}$ (in atmospheres), the number of moles of gas created over time is (for UHMW-PE, PTFE, and EPDM)

$$
\begin{aligned}
& \text { Moles gas created }=\text { molar gas creation rate }(\mathrm{mol} / \mathrm{g} \text { polymer/year }) * \mathrm{p}_{\mathrm{T}}(\mathrm{atm}) * \text { mass of polymer } \\
& (\mathrm{g}) * \text { exposure time }(\mathrm{y})
\end{aligned}
$$

Equation 1 is valid at least over the range of time investigated, two years for UHMW -PE and PTFE, and 14 months for EPDM. 
For Vespel ${ }^{\circledR}$, the amount of $\mathrm{H}_{2}$ created per single exposure (independent of exposure time) is

Moles $\mathrm{H}_{2}$ created/single exposure = molar gas creation rate $(\mathrm{mol} / \mathrm{g}$ Vespel $® /$ single exposure $) *$ mass of polymer $(\mathrm{g})$

Equation 2 is valid at least over the range of time investigated for Vespel ${ }^{\circledR}$, two years, and for tritium partial pressure of $1 \mathrm{~atm}$ or less. It is conservative, in the sense that the time to achieve this stable ratio is less than three months but otherwise undetermined (discussed above).

\subsection{Summary}

Gas production data from past experiments has been analyzed to provide useful estimates of gas production rates for several polymers. These experiments exposed polymer samples to initially 1 atmosphere pure tritium at ambient temperature in closed containers. The production rates are expressed in moles of gas produced per gram polymer per year, except for Vespel ${ }^{\circledR}$ which is moles of gas produce per gram polymer for each exposure.

\begin{tabular}{|c|c|}
\hline Material & $\begin{array}{l}\text { Radiolytic Production Rate and Gas Species Produced, } \\
\text { initially exposed to } 1 \mathrm{~atm} \text { tritium at ambient temperature } \\
\text { in closed container }\end{array}$ \\
\hline UHMW-PE (unfilled) & $1.2 * 10^{-3} \mathrm{~mol} \mathrm{H}_{2} / \mathrm{g}$ UHMW-PE/year \\
\hline PTFE (unfilled) & $4.0^{*} 10^{-5} \mathrm{~mol}(\mathrm{H}, \mathrm{T}) \mathrm{F} / \mathrm{g}$ PTFE$/$ year \\
\hline Vespel $\AA$ SP-1 & $1.1 * 10^{-4} \mathrm{~mol} \mathrm{H}_{2} / \mathrm{g}$ Vespel ${ }^{\circledR} /$ single exposure \\
\hline EPDM (filled) & $1.04 * 10^{-3} \mathrm{~mol}$ gas $\left(\mathrm{H}_{2}, \mathrm{HT}\right) / \mathrm{g}$ filled EPDM/year \\
\hline EPDM (unfilled) & $2.84 * 10^{-3} \mathrm{~mol}$ gas $\left(\mathrm{H}_{2}, \mathrm{HT}\right) / \mathrm{g}$ UNfilled EPDM/year \\
\hline
\end{tabular}

Table 5-1 Summary of Radiolytic Production Rates for Polymers Studied

In addition to these production rates, the utility of polymer filler in decreasing the gas production per unit mass for EPDM was demonstrated.

\subsection{References}

1. Clark, E.; Shanahan, K. "Effects of Tritium Exposure on UHMW-PE, PTFE, and Vespel®". Report WSRC-STI-2006-00049, Savannah River National Laboratory, US DOE Savannah River Site, Aiken SC (31 May 2006), OSTI ID 891658.

2. Clark, E. "Effects of Tritium Gas Exposure on EPDM Elastomer". Report SRNL-2009-00801, Savannah River National Laboratory, US DOE Savannah River Site, Aiken SC (11 December 2009), OSTI ID 969294.

3. J. Crank, G.S. Park (eds.). Diffusion in Polymers. Academic Press, London, UK (1968), p. 5. 